\title{
Immunohistochemical study of $\beta$-catenin and functionally related molecular markers in tongue squamous cell carcinoma and its correlation with cellular proliferation
}

\author{
XIA YUN ${ }^{1}$, LIHONG WANG $^{2,4}$, LEI CAO $^{3}$, NORIHIKO OKADA $^{2}$ and YOSHIO MIKI ${ }^{1}$ \\ ${ }^{1}$ Department of Molecular Genetics, Medical Research Institute, Tokyo Medical and Dental University; \\ Departments of ${ }^{2}$ Diagnostic Oral Pathology, and ${ }^{3}$ Oral Pathology, Oral Restitution, Oral Health Sciences, \\ Graduate School of Tokyo Medical and Dental University, Tokyo, Japan; ${ }^{4}$ Department of Bioengineering, \\ School of Sciences, Graduate School of Northeastern University, Shenyang, P.R. China
}

Received November 30, 2009; Accepted February 26, 2010

DOI: 10.3892/ol_00000077

\begin{abstract}
. $\beta$-catenin plays an important role in the maintenance of cell adhesion and is a key component of the Wnt signaling pathway. However, little is known about its prognostic significance or its role in tumor progression in tongue squamous cell carcinoma (SCC). This study conducted an immunohistochemical analysis of the expression of $\beta$-catenin. Moreover, its possible correlation with clinical parameters and with the expression of the functionally related molecular markers cyclin D1 and p53 was evaluated in 50 cases of tongue SCC and 10 cases of normal tongue epithelium. The ki-67 labeling index (LI) was also examined to evaluate cellular proliferation. Our results showed a higher frequency of abnormal $\beta$-catenin expression, positive cyclin D1 and p53 expression, and a significantly higher ki-67 LI in the tongue SCC samples compared with normal tongue epithelium $(\mathrm{P}<0.05)$. Abnormal $\beta$-catenin and a higher ki-67 expression was significantly associated with moderately or poorly differentiated carcinoma $(\mathrm{P}<0.05)$. Cyclin D1-positive immunostaining showed a statistically significant association with lymph node metastasis $(\mathrm{P}<0.05)$. Furthermore, the abnormal expression of $\beta$-catenin significantly correlated with a higher ki-67 LI and p53 expression $(\mathrm{P}<0.05)$; however, there was no correlation with cyclin $\mathrm{D} 1$ expression $(\mathrm{P}>0.05)$. Taken together, our results suggest
\end{abstract}

Correspondence to: Dr Yoshio Miki, Department of Molecular Genetics, Medical Research Institute, Tokyo Medical and Dental University, 1-5-45 Yushima, Bunkyo-ku, Tokyo 113-8510, Japan

E-mail: miki.mgen@mri.tmd.ac.jp

Dr Norihiko Okada, Department of Diagnostic Oral Pathology, Oral Restitution, Oral Health Sciences, Graduate School of Tokyo Medical and Dental University, 1-5-45 Yushima, Bunkyo-ku, Tokyo 113-8549, Japan

E-mail: nokd.opth@tmd.ac.jp

Key words: tongue squamous cell carcinoma, immunohistochemistry, $\beta$-catenin, cyclin D1, p53, cellular proliferation that abnormal $\beta$-catenin expression is related to the impaired cellular differentiation and proliferation involved in tumor progression in tongue SCC.

\section{Introduction}

The multifunctional protein $\beta$-catenin was initially described as a cell-cell adhesion molecule that interacts directly with E-cadherin and, through its association with $\alpha$-catenin, creates a link between cadherin and the actin cytoskeleton (1). Aberrant function of the cadherin-catenin system results in increased cell motility, invasion and metastasis in many epithelial carcinomas $(2,3)$. $\beta$-catenin also functions as a critical downstream mediator of the Wnt signaling pathway during embryonic development and tumorigenesis (4-7). Under normal conditions, $\beta$-catenin is present in a submembranous location. The level of unbound free cytoplasmic $\beta$-catenin is regulated by the adenomatous polyposis coli (APC) tumor suppressor protein, axin and the glycogen synthase kinase- $3 \beta$ (GSK-3 $\beta$ ) complex, which phosphorylates $\beta$-catenin resulting in rapid ubiquitin-proteasome degradation (8). Mutations in APC, axin or $\beta$-catenin itself, as well as the activation of the Wnt signaling pathway, have been shown to promote the accumulation of $\beta$-catenin in the cytoplasm with a subsequent translocation of the protein into the nucleus. In the nucleus, $\beta$-catenin functions as an oncogene through its interaction with the transcription factor TCF/LEF complex, which mediates the expression of such target genes as cyclin D1 and is important in both cell cycle control and cellular proliferation (9-12).

$\beta$-catenin has also been functionally linked to the p53 pathway. High levels of p53 promote $\beta$-catenin degradation by multiple E3-ubiquitin ligases, independent of N-terminal phosphorylation $(13,14)$. The deregulation of $\beta$-catenin induces $\mathrm{p} 53$ via $\mathrm{ARF} / \mathrm{Mdm} 2$ modulation $(15,16)$, thereby protecting against the oncogenic effects of $\beta$-catenin. Altered $\beta$-catenin expression has been demonstrated in a variety of human cancer types (17-21). However, information regarding its prognostic significance and role in tumor progression in tongue squamous cell carcinoma (SCC) is limited. Thus, we investigated the expression of $\beta$-catenin and the functionally 
Table I. Details regarding the primary antibodies used in the present study.

\begin{tabular}{llcll}
\hline Antigen & Clone & Dilution & Antigen retrieval & Source \\
\hline$\beta$-catenin & E-5 & $1: 100$ & MW, $15 \mathrm{~min}$ & Santa Cruz Biotechnology (USA) \\
p53 & DO-1 & $1: 100$ & AC, $121^{\circ} \mathrm{C}, 15 \mathrm{~min}$ & Santa Cruz Biotechnology (USA) \\
cyclin D1 & P2D11F11 & $1: 30$ & AC, $121^{\circ} \mathrm{C}, 15 \mathrm{~min}$ & Novacastra (Newcastle, UK) \\
ki-67 & MIB-1 & $1: 75$ & AC, $121^{\circ} \mathrm{C}, 15 \mathrm{~min}$ & Dako Cytomation (Denmark) \\
\hline
\end{tabular}

MW, microwave; AC, autoclave.

related molecular markers cyclin D1 and p53 in 50 cases of tongue SCC and 10 cases of tumor-free normal tongue epithelium by immunohistochemistry. The expression of the ki-67 antigen was also examined to evaluate cellular proliferation.

\section{Materials and methods}

Study population and tissue samples. Specimens from 50 patients with tongue SCC were obtained. Patients were treated at the Tokyo Medical and Dental University Hospital, Japan, between 2004 and 2006. The patients received no chemotherapy or radiotherapy prior to primary tumor surgical resection. Patients included 19 (38\%) females and 31 (62\%) males, with a mean age of 58 years (range 22-82). Tumor size, lymph node status, clinical stage and the histological grade of tumor differentiation were recorded. Tumor stage was classified according to the TNM classification of the International Union against Cancer. Tumor histological grading was carried out according to the World Health Organization histological grading of cancer (22). Follow-up for the 50 patients ranged from 12 to 60 months (median 40). Three patients were lost during follow-up. Ten samples of normal tongue epithelium, obtained from tumor-free areas from patients with tongue SCC, were also studied as controls. The procedures followed were in accordance with the ethical standards established by the Ethics Committee of Tokyo Medical and Dental University.

Immunohistochemistry. For all tongue SCC cases, serial 4- $\mu \mathrm{m}$ sections were cut from formalin-fixed, paraffin-embedded tissue blocks and mounted on silanized slides. One section was stained with hematoxylin and eosin and examined to confirm the original diagnosis and histological grade; the other section was used for immunohistochemical staining. Staining was performed using the standard avidin-biotin complex method (SAB-PO kit; Nichirei Bioscience, Tokyo, Japan). The sections were deparaffinized with xylene, rehydrated through a graded ethanol series and rinsed in running water. They were then treated with $0.01 \mathrm{M}$ citrate buffer $(\mathrm{pH}$ 6.0) for heatinduced antigen retrieval (Table I). Endogenous peroxidase activity was quenched by immersing the sections in methanol containing $0.3 \%$ hydrogen peroxide at room temperature for 20 min. To block the non-specific binding of the primary antibody, the slides were treated with $10 \%$ normal rabbit serum for $30 \mathrm{~min}$ at room temperature. The sections were then reacted with the primary monoclonal antibody overnight in a moist chamber. After thoroughly rinsing the sections with phosphate-buffered saline (PBS), they were incubated with biotinylated anti-mouse $\operatorname{Ig} \mathrm{A}+\mathrm{G}+\mathrm{M}$ secondary antibody. After washing with PBS, an avidin-biotin-peroxidase complex was applied for $30 \mathrm{~min}$. Finally, the signals were visualized with 3,3'-diaminobenzidine tetrahydrochloride and counterstained with hematoxylin. Negative control experiments were carried out by replacing the primary antibody with PBS. Immunohistochemical evaluations were carried out using 10 random high-power fields (x400), one of which was the invasion front, which was regarded as the most indicative of tumor cell biological activity.

$\beta$-catenin immunostaining was assessed using a previously described scoring method (20). Staining was evaluated semi-quantitatively by comparing the intensity and cellular localization of the positive signals with those in the adjacent normal epithelium as an internal positive control. Staining was then recorded as normal or abnormal. Normal described uniform membranous staining, strong and similar to that in the internal controls. Partial loss (mixed areas of positive and negative cells with normal membranous staining) or complete loss (uniformally negative) of normal membranous staining, or altered cellular distribution in the cytoplasm and/or nucleus were defined as abnormal.

As part of our immunohistochemical analysis of cyclin D1 and p53, positive tumor cells were identified by the number of brown-stained nuclei out of the total number of tumor cells. The samples were classified as positive when $>10 \%$ of the cells had a brown nucleus. ki-67 activity was evaluated using the labeling index (LI) by determining the percentage of ki-67positive cells; our results are presented as the mean $\pm \mathrm{SD}$.

Statistical analysis. The data were analyzed using SPSS 13.0 for Windows. Associations between our immunohistochemical staining results and clinicopathological findings were evaluated using the Chi-square or Fisher's exact test. The significance of our results for ki-67 was assessed using the Mann-Whitney U test. Survival analyses were calculated using the Kaplan-Meier method, while differences in the survival curves were compared using the log-rank test. For all analyses, $\mathrm{P}<0.05$ was deemed significant.

\section{Results}

$\beta$-catenin expression. Table II shows the results of our analysis of $\beta$-catenin expression in samples taken from patients with tongue SCC and normal tongue epithelium. Abnormal $\beta$-catenin expression was detected in 34 of the 50 cases 
Table II. Expression of $\beta$-catenin, functionally related molecular markers and ki-67 in tongue SCC and normal tongue tissues.

\begin{tabular}{|c|c|c|c|c|c|c|c|c|c|c|}
\hline & \multicolumn{3}{|c|}{$\beta$-catenin } & \multicolumn{3}{|c|}{ cyclin D1 } & \multicolumn{3}{|c|}{ p53 } & \multirow{2}{*}{$\frac{\mathrm{ki}-67}{\text { Mean } \pm \text { SD }}$} \\
\hline & Abnormal & Normal & Total & + & - & Total & + & - & Total & \\
\hline Tongue SCC & 34 & 16 & 50 & 29 & 21 & 50 & 26 & 24 & 50 & $31.8 \pm 9.1$ \\
\hline NTT & 0 & 10 & 10 & 1 & 9 & 10 & 0 & 10 & 10 & $9.3 \pm 5.2$ \\
\hline P-value & 0.0003 & & & 0.012 & & & 0.007 & & & 0.0001 \\
\hline
\end{tabular}

Tongue SCC, tongue squamous cell carcinoma; NTT, normal tongue tissues.
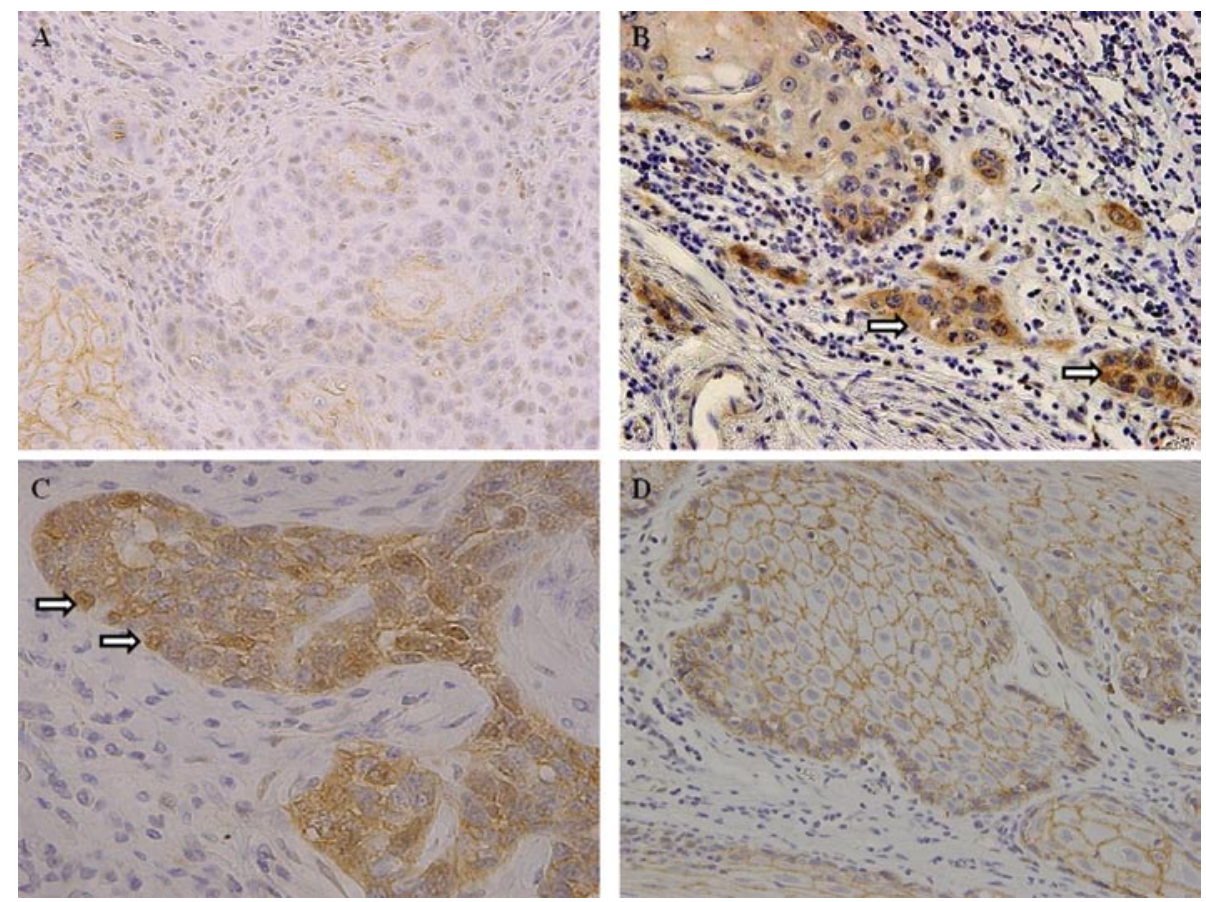

Figure 1. Immunohistochemical staining for $\beta$-catenin. (A) Abnormal expression of $\beta$-catenin in tongue SCC; partial loss of normal membranous staining (original magnification, x200). (B) Abnormal expression of $\beta$-catenin in tongue SCC; altered cellular distribution in the cytoplasm (x200). (C) Abnormal expression of $\beta$-catenin in tongue SCC; altered cellular distribution in the nucleus (x400). (D) Normal expression of $\beta$-catenin in tongue SCC; continuous and linear membranous staining (x200).

(68\%). Of these cases, 23 exhibited completely or partially absent $\beta$-catenin membranous staining (Fig. 1A), while the remaining 11 cases showed a loss of membranous expression combined with an altered distribution in the cytoplasm and/or nucleus (Fig. 1B and C). Of the 50 cases, 16 (32\%) exhibited continuous linear membranous staining, similar to that in the normal tongue tissues (Fig. 1D). In contrast, among the 10 normal tongue epithelial samples, $\beta$-catenin was expressed in a strong, linear membranous pattern with no staining in the cytoplasm and/or nucleus. Thus, abnormal $\beta$-catenin expression was a frequent finding in tongue SCC but not in normal tongue epithelium $(\mathrm{P}=0.0003)$.

Cyclin D1, p53 and ki-67 expression. Immunoreactivity with an anti-cyclin D1 antibody was observed in the nucleus in that $29(58 \%)$ of the 50 tongue SCC cases showed cyclin D1-positive expression (Fig. 2A), while the remaining cases were negative. In the samples of normal epithelium, weak or faint nuclear staining was rarely observed (Fig. 2B), and only one of the 10 cases showed a low level of cyclin D1-positive expression. Thus, cyclin D1 expression was significantly higher in tongue $\mathrm{SCC}$ than in normal tongue epithelium $(\mathrm{P}=0.012)$ (Table II).

In $26(52 \%)$ of the 50 cases of tongue SCC, nuclear p53 accumulation was observed in most of the tumor cells (Fig. 3A), whereas none of the 10 cases of normal tongue epithelium exhibited a reaction against p53 (Fig. 3B). Thus, the positive rate was significantly higher in tongue SCC than in normal epithelium $(\mathrm{P}=0.007)$ (Table II). Cellular proliferation was assessed based on the ki-67 LI. In the tongue SCC samples, a large number of ki-67-positive cells was observed (Fig. 4A), with the mean ki-67 LI being 31.8 \pm 9.1 compared to $10.3 \pm 5.2$ for the normal tongue epithelial samples. Moreover, in the normal samples, nuclear ki-67 reactivity was only detectable in the basal and para-basal layers (Fig. 4B). Thus, the ki-67 LI was significantly higher in tongue SCC than in normal tongue epithelium $(\mathrm{P}=0.0001)$ (Table II). 

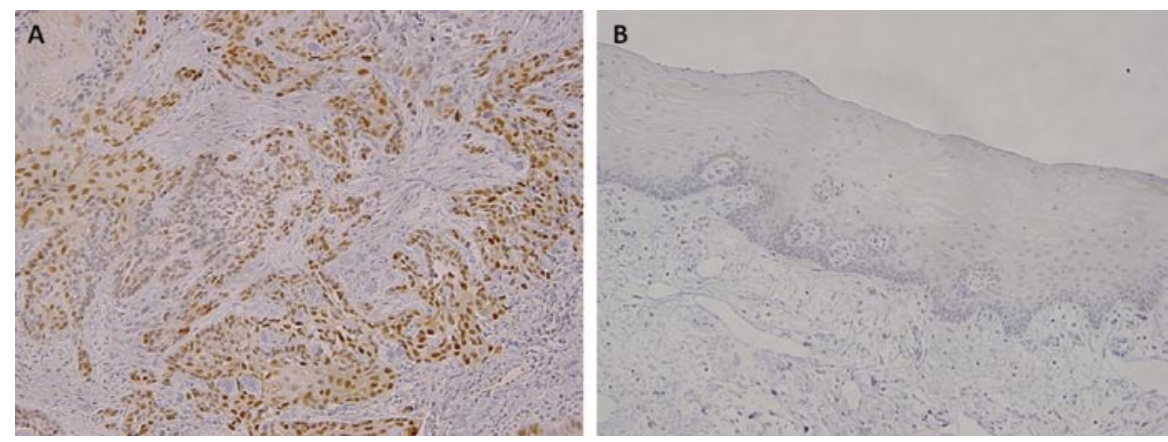

Figure 2. Immunohistochemical staining for cyclin D1. (A) In tongue SCC, the positive staining of cyclin D1 was observed in most tumor cells (original magnification, x100). (B) Negative staining in normal tongue epithelium (x100) is shown.
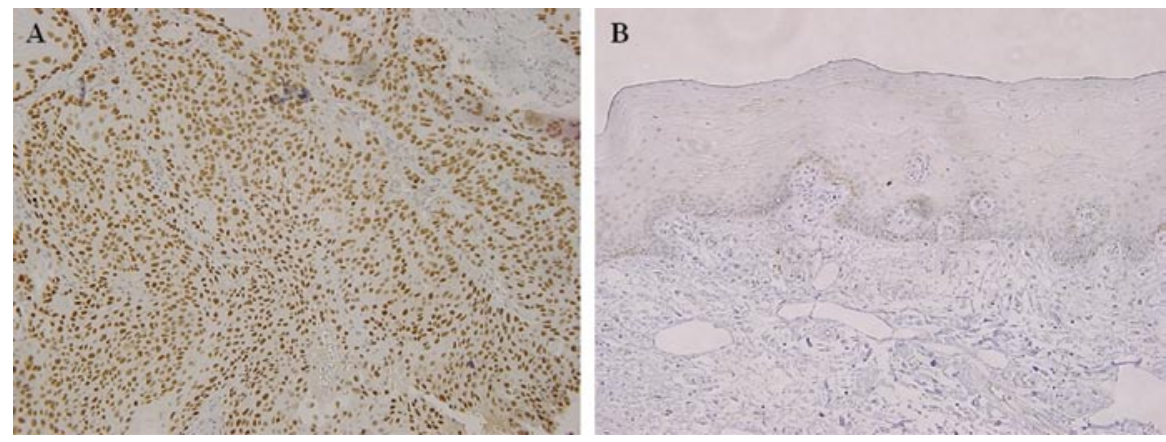

Figure 3. Immunohistochemical staining for p53. (A) In tongue SCC, the positive staining of p53 was observed in most tumor cells (original magnification, $\mathrm{x} 100)$. (B) Negative staining in normal tongue epithelium (x100) is shown.
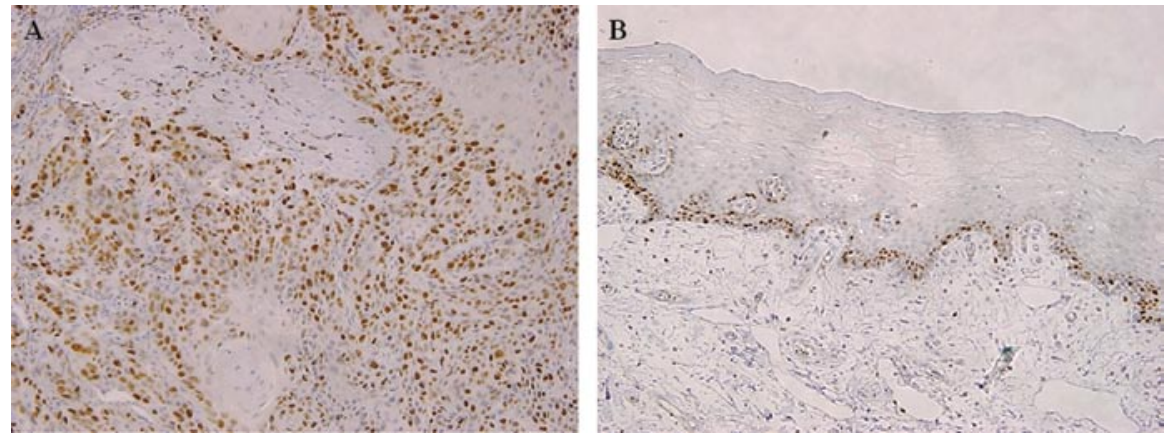

Figure 4. Immunohistochemical staining for ki-67. (A) In tongue SCC, the positive staining of ki-67 was observed in most tumor cells (original magnification, $\mathrm{x} 100$ ). (B) A low level of positive cells only in the basal and para-basal layers of normal tongue epithelium (x100) is shown.

Correlation between $\beta$-catenin, cyclin D1, p53 and ki-67 expression and clinicopathological features in tongue SCC. Table III shows the correlation between $\beta$-catenin expression and various clinicopathological features. A significant correlation was noted between abnormal $\beta$-catenin expression and histological differentiation (moderately or poorly differentiated; $\mathrm{P}=0.002)$. However, no significant correlation was found between abnormal $\beta$-catenin expression and age, gender, tumor size, clinical stage or lymph node metastasis $(\mathrm{P}>0.05)$. Cyclin D1 expression in the tongue SCC samples was significantly correlated with lymph node metastasis $(\mathrm{P}=0.010)$, but no correlation was found between other clinical parameters such as age, gender, $\mathrm{T}$ status or clinical stage $(\mathrm{P}>0.05)$. No correlation was found between p53 nuclear accumulation and any of the clinicopathological features examined in this study $(\mathrm{P}>0.05)$. Cellular proliferation, as assessed by ki-67 expression, was significantly associated with histological differentiation (moderately or poorly differentiated; $\mathrm{P}=0.011$ ).

Correlation of $\beta$-catenin expression with that of functionally related molecular markers and ki-67 in tongue SCC. Table IV shows the correlation between the expression of $\beta$-catenin, as detected by immunohistochemical analysis, and that of the functionally related molecular markers cyclin D1 and p53, and ki-67. Abnormal $\beta$-catenin expression was significantly positively correlated with ki-67 expression $(\mathrm{P}=0.030)$. A positive correlation was also detected between the abnormal expression of $\beta$-catenin and the positive p53 expression $(\mathrm{P}=0.014)$, but not the cyclin $\mathrm{D} 1$-positive expression $(\mathrm{P}>0.05)$. 
Table III. Correlation between immunohistochemistry and clinicopathological features in the tongue SCC.

\begin{tabular}{|c|c|c|c|c|c|c|c|c|c|c|}
\hline & \multicolumn{3}{|c|}{$\beta$-catenin } & \multicolumn{3}{|c|}{ cyclin D1 } & \multicolumn{3}{|c|}{ p53 } & \multirow{2}{*}{$\frac{\text { ki-67 }}{\text { Mean } \pm \text { SD }}$} \\
\hline & Abnormal & Normal & Total & + & - & Total & + & - & Total & \\
\hline \multicolumn{11}{|l|}{ Age } \\
\hline$\geq 60$ & 16 & 10 & 26 & 14 & 12 & 26 & 14 & 12 & 26 & $32.2 \pm 9.8$ \\
\hline$<60$ & 18 & 6 & 24 & 15 & 9 & 24 & 12 & 12 & 24 & $31.4 \pm 7.5$ \\
\hline P-value & NS & & & NS & & & NS & & & NS \\
\hline \multicolumn{11}{|l|}{ Gender } \\
\hline Male & 23 & 8 & 31 & 20 & 11 & 31 & 17 & 14 & 31 & $32.7 \pm 10.1$ \\
\hline Female & 11 & 8 & 19 & 9 & 10 & 19 & 9 & 10 & 19 & $30.9 \pm 9.6$ \\
\hline P-value & NS & & & NS & & & NS & & & NS \\
\hline \multicolumn{11}{|l|}{ Tumor size } \\
\hline $\mathrm{T} 1+\mathrm{T} 2$ & 23 & 9 & 32 & 19 & 13 & 32 & 15 & 17 & 32 & $32.1 \pm 10.4$ \\
\hline $\mathrm{T} 3+\mathrm{T} 4$ & 11 & 7 & 18 & 10 & 8 & 18 & 11 & 7 & 18 & $31.5 \pm 8.9$ \\
\hline P-value & NS & & & NS & & & NS & & & NS \\
\hline \multicolumn{11}{|c|}{ Nodal metastasis } \\
\hline Negative & 21 & 9 & 30 & 13 & 17 & 30 & 13 & 17 & 30 & $30.5 \pm 8.2$ \\
\hline Positive & 13 & 7 & 20 & 16 & 4 & 20 & 13 & 7 & 20 & $33.1 \pm 9.4$ \\
\hline P-value & NS & & & 0.010 & & & NS & & & NS \\
\hline \multicolumn{11}{|c|}{ Clinical stage } \\
\hline Stage 1-2 & 18 & 6 & 24 & 11 & 13 & 24 & 11 & 13 & 24 & $30.4 \pm 10.8$ \\
\hline Stage 3-4 & 16 & 10 & 26 & 18 & 8 & 26 & 15 & 11 & 26 & $33.2 \pm 8.7$ \\
\hline P-value & NS & & & NS & & & NS & & & NS \\
\hline \multicolumn{11}{|c|}{ Differentiation } \\
\hline Well & 10 & 13 & 23 & 14 & 9 & 23 & 11 & 12 & 23 & $25.8 \pm 11.4$ \\
\hline Moderate & 18 & 2 & 20 & 10 & 10 & 20 & 12 & 8 & 20 & $31.8 \pm 9.8$ \\
\hline Poor & 6 & 1 & 7 & 5 & 2 & 7 & 3 & 4 & 7 & $37.4 \pm 10.3$ \\
\hline P-value & 0.002 & & & NS & & & NS & & & 0.011 \\
\hline
\end{tabular}

NS, not significant.

Table IV. Correlation between the expression of $\beta$-catenin and molecular markers, and ki-67 in tongue SCC.

\begin{tabular}{|c|c|c|c|c|c|c|c|}
\hline \multirow[t]{2}{*}{$\beta$-catenin } & \multicolumn{3}{|c|}{ cyclin D1 } & \multicolumn{3}{|c|}{ p53 } & \multirow{2}{*}{$\frac{\mathrm{ki}-67}{\text { Mean } \pm \mathrm{SD}}$} \\
\hline & + & - & Total & + & - & Total & \\
\hline Abnormal & 20 & 14 & 34 & 22 & 12 & 34 & $38.0 \pm 10.6$ \\
\hline Normal & 9 & 7 & 16 & 4 & 12 & 16 & $25.6 \pm 9.7$ \\
\hline P-value & NS & & & 0.014 & & & 0.030 \\
\hline
\end{tabular}

NS, not significant.

Survival analysis and expression of $\beta$-catenin in tongue SCC. Data collected during the follow-up period for the 47 tongue SCC patients showed that $76 \%(36 / 47)$ of the subjects were alive and disease-free, whereas $17 \%(8 / 47)$ had succumbed to tongue SCC, while 4\% (2/47) had succumbed to other causes. As the median follow-up period was not as long as 5 years for all 47 patients, we performed a 3-year survival analysis of the 47 patients using the Kaplan-Meier method. No signifi- cant difference in survival rate was found between those with abnormal and those with normal $\beta$-catenin expression (data not shown).

\section{Discussion}

This study employed immunohistochemistry to evaluate the expression of $\beta$-catenin in patients with tongue SCC, as well 
as its correlation with functionally related molecular markers and clinicopathological features. ki-67 LI was also examined to evaluate cellular proliferation.

$\beta$-catenin is a member of the cadherin-catenin complex that mediates homotypic cell-cell adhesion and is an important component of the Wnt signaling pathway. Numerous studies have suggested that there is a correlation between altered $\beta$-catenin expression and the progression of various human malignancies (17-21). In this study, abnormal $\beta$-catenin expression was observed in $68 \%$ of 50 cases of tongue SCC, and the frequency of the expression was significantly higher than in normal tongue epithelium. These results suggest that $\beta$-catenin plays an important role in tumor progression in patients with tongue SCC.

The maintenance of a high degree of cellular differentiation largely relies on the function of the cadherin-mediated adhesion system (23). Our current results show a definite correlation between abnormal $\beta$-catenin expression and histological differentiation (i.e., moderate or poor differentiation) in tongue SCC. This suggests the possible involvement of $\beta$-catenin in tongue SCC progression and in predicting future malignant behavior. Furthermore, changes in the expression of cell adhesion molecules are considered to play important roles in facilitating the processes of metastasis and invasion. Lymph node metastasis is an important prognostic factor and has been reported in 20-50\% of tongue cancer types (24-26). Results of the present study showed that abnormal $\beta$-catenin expression did not significantly correlate with lymph node metastasis. On the other hand, numerous authors reported significant associations between aberrant $\beta$-catenin expression and lymph node metastasis $(27,28)$. However, large-scale studies are required to reach a definitive conclusion. As the median follow-up period in this study was not 5 years for all patients, whether a significant correlation existed between the 5 -year survival rate and $\beta$-catenin expression in patients with tongue SCC could not be determined.

Positive staining for cyclin D1 was noted in $58 \%$ of the tongue SCC samples in this study. This value was significantly higher than that for normal tongue epithelium, consistent with our previous report (29). A significant association was noted between cyclin D1 expression and lymph node metastasis in the tongue SCC. Additionally, it has been shown that cyclin $\mathrm{D} 1$ is a target of $\beta$-catenin, and its activation results in the loss of cell cycle control and an increased cellular proliferation in colon (10), breast (11) and pancreatic cancer (12). Nevertheless, we found that abnormal $\beta$-catenin expression did not correlate with cyclin D1 expression, although cyclin D1 was expressed in a high percentage of the tongue SCC samples. Our results indicate that cyclin D1 expression may be regulated independently of the $\beta$-catenin/TCF complex in tongue cancer, in contrast to that in colorectal cancer types (10).

We detected positive staining for p53 in $52 \%$ of the 50 cases of tongue SCC. However, no relationship was noted with any clinical parameter. Nevertheless, a significant correlation with abnormal $\beta$-catenin expression was detected in the tongue SCC samples. Although the antibody used in our study was able to detect both wild-type and mutated p53, it is widely accepted that immunohistochemical p53 expression is based on the prolonged half-life of the mutant protein compared with wild-type. A number of studies have demonstrated that mutant p53 regulates the expression and promoter activity of endogenous genes such as c-myc (30), EGFR (31) and PCNA (32), causing an increase in oncogenic activity. Additionally, some studies have pointed out the existence of regulatory mechanisms between $\beta$-catenin and p53. It was previously shown that deregulated $\beta$-catenin led to p53 induction by ARF/Mdm 2 modulation $(13,14)$. On the other hand, high levels of activated wild-type p53, elicited by malignancy-inducing stress signals, can promote the degradation of $\beta$-catenin by multiple E3-ubiquitin ligases, independent of $\mathrm{N}$-terminal phosphorylation $(15,16)$. This correlation has been noted in lymph node metastasis-negative cases of breast cancer (33) and hepatocellular carcinoma (34). Our results suggest the regulation of $\beta$-catenin activation in the presence of wild-type p53. Moreover, they suggest that, following the mutation of p53, $\beta$-catenin is stabilized and free to promote tumor development in tongue SCC. Of note is that the mutation of p53 does not always correlate with its expression in human cancer types, such as the creation of a stop codon, a frameshift mutation, or a nonsense mutation that result in truncated proteins which are not detected by immunohistochemistry (35). Thus, even though the correlation between $\beta$-catenin and p53 may be important in the tumorigenesis of tongue SCC, it should be interpreted cautiously and requires further understanding.

As we suspected that abnormal $\beta$-catenin expression may have biological significance in tongue SCC, we examined its relationship with ki-67 expression. Our results suggest that abnormal $\beta$-catenin expression is significantly associated with an increased ki-67 LI vs. a normal $\beta$-catenin expression in tongue SCC. Mutations in APC and $\beta$-catenin are important mechanisms for the activation of $\beta$-catenin in various cancer types (36), but there is no evidence available in head and neck cancers $(37,38)$ and these mutations have not been reported in patients with tongue SCC. Thus, additional molecular events may also be important in the deregulation of $\beta$-catenin in tongue SCC and should be investigated further in studies combining molecular and pathological analyses.

We conclude that abnormal $\beta$-catenin expression is associated with poor differentiation and may be related to the cellular proliferation involved in tumor progression in tongue SCC.

\section{Acknowledgements}

We would like to thank all members of the Department of Diagnostic Oral Pathology, Graduate School of Tokyo Medical and Dental University for the excellent technical assistance throughout the study.

\section{References}

1. Ozawa M, Baribault $\mathrm{H}$ and Kemler R: The cytoplasmic domain of the cell adhesion molecule uvomorulin associates with three independent proteins structurally related in different species. EMBO J 8: 1711-1717, 1989.

2. Hirohashi $S$ : Inactivation of the E-cadherin-mediated cell adhesion system in human cancers. Am J Pathol 153: 333-339, 1998.

3. Gumbiner BM: Cell adhesion: the molecular basis of tissue architecture and morphogenesis. Cell 84: 345-357, 1996.

4. Miller JR and Moon RT: Signal transduction through betacatenin and specification of cell fate during embryogenesis. Genes Dev 10: 2527-2539, 1996. 
5. Shtutman M, Zhurinsky J, Simcha I, Albanese C, D'Amico M, Pestell R and Ben-Ze'ev A: The cyclin D1 gene is a target of the beta-catenin/LEF-1 pathway. Proc Natl Acad Sci USA 96: $5522-5527,1999$

6. He TC, Sparks AB, Rago C, et al: Identification of c-MYC as a target of the APC pathway. Science 281: 1509-1512, 1998.

7. Brabletz T, Jung A, Dag S, Hlubek F and Kirchner T: Beta-catenin regulates the expression of the matrix metalloproteinase-7 in human colorectal cancer. Am J Pathol 155: 1033-1038, 1999.

8. Aberle H, Bauer A, Stappert J, Kispert A and Kemler R: Betacatenin is a target for the ubiquitin-proteasome pathway. EMBO J 16: 3797-3804, 1997.

9. Behrens J, von Kries JP, Kuhl M, Bruhn L, Wedlich D, Grosschedl $\mathrm{R}$ and Birchmeier W: Functional interaction of beta-catenin with the transcription factor LEF-1. Nature 382: 638-642, 1996

10. Tetsu $\mathrm{O}$ and McCormick F: Beta-catenin regulates expression of cyclin D1 in colon carcinoma cells. Nature 398: 422-426, 1999.

11. Lin SY, Xia W, Wang JC, et al: Beta-catenin, a novel prognostic marker for breast cancer: its roles in cyclin D1 expression and cancer progression. Proc Natl Acad Sci USA 97: 4262-4266, 2000.

12. Qiao Q, Ramadani M, Gansauge S, Gansauge F, Leder G and Beger HG: Reduced membranous and ectopic cytoplasmic expression of beta-catenin correlates with cyclin D1 overexpression and poor prognosis in pancreatic cancer. Int $\mathrm{J}$ Cancer 95: 194-197, 2001

13. Damalas A, Ben-Ze'ev A, Simcha I, et al: Excess beta-catenin promotes accumulation of transcriptionally active p53. EMBO J 18: 3054-3063, 1999.

14. Damalas A, Kahan S, Shtutman M, Ben-Ze'ev A and Oren M Deregulated beta-catenin induces a p53- and ARF-dependent growth arrest and cooperates with Ras in transformation. EMBO J 20: 4912-4922, 2001.

15. Matsuzawa SI and Reed JC: Siah-1, SIP and Ebi collaborate in a novel pathway for beta-catenin degradation linked to p53 responses. Mol Cell 7: 915-926, 2001.

16. Liu J, Stevens J, Rote CA, et al: Siah-1 mediates a novel betacatenin degradation pathway linking p53 to the adenomatous polyposis coli protein. Mol Cell 7: 927-936, 2001.

17. Maruyama K, Ochiai A, Akimoto S, Nakamura S, Baba S, Moriya Y and Hirohashi S: Cytoplasmic beta-catenin accumulation as a predictor of hematogenous metastasis in human colorectal cancer. Oncology 59: 302-309, 2000.

18. Karayiannakis AJ, Nakopoulou L, Gakiopoulou $H$ Keramopoulos A, Davaris PS and Pignatelli M: Expression patterns of beta-catenin in in situ and invasive breast cancer. Eur J Surg Oncol 27: 31-36, 2001.

19. Jawhari A, Jordan S, Poole S, Browne P, Pignatelli M and Farthing MJ: Abnormal immunoreactivity of the E-cadherincatenin complex in gastric carcinoma: relationship with patient survival. Gastroenterology 112: 46-54, 1997.

20. Papadavid E, Pignatelli M,Zakynthinos S, Krausz T and Chu AC: Abnormal immunoreactivity of the E-cadherin/catenin (alpha-, beta- and gamma-) complex in premalignant and malignant nonmelanocytic skin tumours. J Pathol 196: 154-162, 2002.

21. Endo K, Ueda T, Ueyama J, Ohta T and Terada T: Immunoreactive E-cadherin, alpha-catenin, beta-catenin and gamma-catenin proteins in hepatocellular carcinoma: relationships with tumor grade, clinicopathologic parameters and patients' survival. Hum Pathol 31: 558-565, 2000.

22. Pindborg JJ, Reichart PA, Smith CJ and van der Waal I: World Health Organisation International Histological Classification of Tumours. Histological Typing of Cancer and Precancer of the Oral Mucosa. 2nd edition. Springer, Berlin, 1997.
23. Lo Muzio L, Staibano S, Pannone G, et al: Beta- and gammacatenin expression in oral squamous cell carcinomas. Anticancer Res 19: 3817-3826, 1999.

24. Ho CM, Lam KH, Wei WI, Lau SK and Lam LK: Occult lymph node metastasis in small oral tongue cancers. Head Neck 14 359-363, 1992.

25. Johnson JT, Barnes EL, Myers EN, Schramm VL Jr, Borochovitz D and Sigler BA: The extracapsular spread of tumors in cervical node metastasis. Arch Otolaryngol 107: 725-729, 1981.

26. Yamazaki H, Inoue T, Yoshida K, et al: Lymph node metastasis of early oral tongue cancer after interstitial radiotherapy. Int J Radiat Oncol Biol Phys 58: 139-146, 2004.

27. Odajima T, Sasaki Y, Tanaka N, et al: Abnormal beta-catenin expression in oral cancer with no gene mutation: correlation with expression of cyclin D1 and epidermal growth factor receptor, Ki-67 labeling index, and clinicopathological features. Hum Pathol 36: 234-241, 2005.

28. Ueda G, Sunakawa H, Nakamori K, et al: Aberrant expression of beta- and gamma-catenin is an independent prognostic marker in oral squamous cell carcinoma. Int J Oral Maxillofac Surg 35: 356-361, 2006.

29. Wang L, Liu T, Nishioka M, Aguirre RL, Win SS and Okada N: Activation of ERK1/2 and cyclin D1 expression in oral tongue squamous cell carcinomas: relationship between clinicopathological appearances and cell proliferation. Oral Oncol 42: 625-631, 2006.

30. Chen TM and Defendi V: Functional interaction of p53 with HPV18 E6, c-myc and H-ras in 3T3 cells. Oncogene 7: 1541-1547, 1992.

31. Horak E, Smith K, Bromley L, LeJeune S, Greenall M, Lane D and Harris AL: Mutant p53, EGF receptor and c-erbB-2 expression in human breast cancer. Oncogene 6: 2277-2284, 1991.

32. Xu J and Morris GF: p53-mediated regulation of proliferating cell nuclear antigen expression in cells exposed to ionizing radiation. Mol Cell Biol 19: 12-20, 1999.

33. Chung GG, Zerkowski MP, Ocal IT, et al: Beta-catenin and p53 analyses of a breast carcinoma tissue microarray. Cancer 100: 2084-2092, 2004.

34. Prange W, Breuhahn K, Fischer F, et al: Beta-catenin accumulation in the progression of human hepatocarcinogenesis correlates with loss of E-cadherin and accumulation of p53, but not with expression of conventional WNT-1 target genes. J Pathol 201: 250-259, 2003.

35. Kastan MB, Onyekwere O, Sidransky D, Vogelstein B and Craig RW: Participation of p53 protein in the cellular response to DNA damage. Cancer Res 51: 6304-6311, 1991.

36. Polakis P: Wnt signaling and cancer. Genes Dev 14: 1837-1851, 2000.

37. Gonzalez MV, Pello MF, Ablanedo P, Suarez C, Alvarez V and Coto E: Chromosome $3 p$ loss of heterozygosity and mutation analysis of the FHIT and beta-cat genes in squamous cell carcinoma of the head and neck. J Clin Pathol 51: 520-524, 1998.

38. Iwai S, Katagiri W, Kong C, Amekawa S, Nakazawa M and Yura Y: Mutations of the APC, beta-catenin, and axin 1 genes and cytoplasmic accumulation of beta-catenin in oral squamous cell carcinoma. J Cancer Res Clin Oncol 131: 773-782, 2005. 